\title{
Early-onset ventilator-associated pneumonia incidence in intensive care units: a surveillance- based study
}

\author{
Philippe Vanhems ${ }^{1,2^{*}}$, Thomas Bénet ${ }^{1,2}$, Nicolas Voirin ${ }^{1,2}$, Jean-Marie Januel ${ }^{3}$, Alain Lepape ${ }^{4}$, Bernard Allaouchiche ${ }^{5}$, \\ Laurent Argaud ${ }^{6}$, Dominique Chassard ${ }^{7}$ and Claude Guérin ${ }^{8}$, for the Study Group
}

\begin{abstract}
Background: The incidence of ventilator-associated pneumonia (VAP) within the first 48 hours of intensive care unit (ICU) stay has been poorly investigated. The objective was to estimate early-onset VAP occurrence in ICUs within 48 hours after admission.

Methods: We analyzed data from prospective surveillance between 01/01/2001 and 31/12/2009 in 11 ICUs of Lyon hospitals (France). The inclusion criteria were: first ICU admission, not hospitalized before admission, invasive mechanical ventilation during first ICU day, free of antibiotics at admission, and ICU stay $\geq 48$ hours. VAP was defined according to a national protocol. Its incidence was the number of events per 1,000 invasive mechanical ventilation-days. The Poisson regression model was fitted from day 2 (D2) to D8 to incident VAP to estimate the expected VAP incidence from D0 to D1 of ICU stay.
\end{abstract}

Results: Totally, 367 (10.8\%) of 3,387 patients in 45,760 patient-days developed VAP within the first 9 days. The predicted cumulative VAP incidence at D0 and D1 was 5.3 (2.6-9.8) and 8.3 (6.1-11.1), respectively. The predicted cumulative VAP incidence was 23.0 (20.8-25.3) at D8. The proportion of missed VAP within 48 hours from admission was 11\% (9\%-17\%).

Conclusions: Our study indicates underestimation of early-onset VAP incidence in ICUs, if only VAP occurring $\geq$ 48 hours are considered to be hospital-acquired. Clinicians should be encouraged to develop a strategy for early detection after ICU admission.

\section{Background}

The epidemiological surveillance of healthcare-associated infections (HAIs) in intensive care units (ICUs) provides clinicians and caregivers with trend descriptions and contributes to HAI prevention [1-4]. When studies from such epidemiological surveillance programs are carried out, standardized definitions of risk factors for HAI must be used. However, these distinctions as well as the terminology adopted change over time. Indeed, in the last Centers for Disease Control and Prevention definition, HAI replaced the term "hospital-acquired infection" [5].

\footnotetext{
* Correspondence: philippe.vanhems@chu-lyon.fr

${ }^{1}$ Hospices Civils de Lyon, Infection Control Unit, Edouard Herriot Hospital, Lyon, France

Full list of author information is available at the end of the article
}

To exclude community-acquired infections, it was acknowledged that a period of 48 hours between ICU admission and the onset of symptoms was required to identify cases as hospital-acquired infections [1-4,6-10]. The time window of 48 hours was first conceived by US National Nosocomial Infection Surveillance (NNIS). The NNIS/National Healthcare Safety Network retained this value for bacterial infections because of their typical incubation period [11]. However, the statement: 1) is both conservative for some microorganisms with longer incubation periods (i.e. Mycoplasma pneumonia) or some viruses (i.e. influenza) and restrictive for others (i.e. Streptococcus pneumoniae) [12], and 2) does not take device exposure into account. In France, nosocomial infection surveillance networks adopted this time period.

\section{Biomed Central}


The main consequence is that HAIs occurring before the second day after admission are not considered.

Early-onset, ventilator-associated pneumonia (VAP), arising within 48 hours after device exposure, should be designated as HAI [5]. However, very few data support this view [13]. It has been noted that colonization of the trachea in the first 24 hours after intubation occurs frequently in head trauma patients and predicts the development of early-onset pneumonia [14]. Because no data on early-onset VAP are readily available, its incidence within 48 hours after ICU admission can be estimated from observed VAP.

Additional assessment of the incidence of very earlyonset VAP is important to discuss these new definitions of hospital-acquired VAP and to draw the attention of clinicians towards early adverse events. The primary objective of the present study was to estimate the incidence of early-onset VAP in ICUs within the first 48 hours after admission.

\section{Methods}

\section{Setting}

Analysis was based on prospective data from 11 ICUs of Lyon hospitals in France. These ICUs participate in a national HAI surveillance network that has been described in detail elsewhere [15]. Briefly, all ICU patients staying 48 hours or more were included in the surveillance program until their ICU discharge. The data were collected prospectively over the year on a standardized collection form, which comprised demographic characteristics, the severity of underlying diseases, risk factors for HAIs, exposure to mechanical ventilation, central venous catheters, urinary catheters, date and site of infection, etiological agents, and patient outcome.

Informed consent was waived because data were extracted from the surveillance database. According to French law, a study like this one does not require ethics committee approval because it is observational and based on a surveillance database approved under national regulations (Comité National Informatique et Liberté).

\section{Inclusion criteria}

Patients discharged between 01/01/2001 and 31/12/ 2009 , hospitalized $\geq 48$ hours in ICUs, were included in the present study if they met the following criteria: 1) first ICU admission, 2) not admitted from hospital, 3) free of antibiotics at the time of ICU admission, 4) neither intubated nor tracheotomized at the time of ICU admission, 5) intubated or tracheotomized during the first 24 hours after ICU admission. Patients admitted from other wards or undergoing tracheal intubation or tracheotomy or antibiotics prior to ICU admission were excluded.

\section{Definitions of VAP}

VAP [16] was defined according to the following:

- Chest X-rays exhibiting lung infiltrates;

- Temperature $>38^{\circ} \mathrm{C}$ or leukocyte count $>12,000$ / $\mathrm{mm}^{3}$ or $<4,000 / \mathrm{mm}^{3}$;

- One of the following: 1) sputum modification, 2) suggestive auscultation, 3) low oxyhemoglobin saturation, or 4) increased pulmonary oxygen consumption; - And 1 of the following: 1) directed bronchoalveolar lavage (BAL)-positive culture at a threshold of $10^{4} \mathrm{cfu} /$ $\mathrm{ml}$ in case of BAL or $10^{3} \mathrm{cfu} / \mathrm{ml}$ in case of nonbronchoscopic protected specimen brushing [17], or 2) fiberoptic bronchoscopy specimen-positive culture at a threshold of $10^{6} \mathrm{cfu} / \mathrm{ml}$, or 3) 1 of the following: positive pleural or blood cultures without any other site of infection, pulmonary or pleural abscess, histopathological evidence of pneumonia or cultures positive for specific agents.

Microbiological specimens were always obtained before the introduction of new antibiotics and as soon as possible after the identification of clinical or radiological criteria of pneumonia. In case of consecutive VAP episodes, only the first episode was considered for analysis.

\section{Statistical analysis}

The primary end-point was the incidence of early-onset VAP during ICU stay. Therefore, the follow-up period in the present study was restricted from day 0 (D0, ICU admission) to D8 of ICU stay. Patients were followed up from admission to VAP occurrence or were censored at the end of mechanical ventilation exposure or at D8 if no VAP had transpired. The enrolled population was described. At each day of this follow-up, the observed number of incident VAP cases, the number of patients at risk for that day, and the main characteristics of patients who developed VAP were recorded. Because the exact hour of the beginning of exposure was not evident, the number of invasive mechanical ventilation days was divided by 2 to estimate mechanical ventilation days at the first and last days. The hypothesis was that, on average, patients were exposed to mechanical ventilation for 12 hours.

Categorical variables were compared by $\mathrm{Chi}^{2}$ test. Continuous variables, expressed as median and interquartile range (IQR), were compared by the Mann-Whitney U test. VAP incidence was expressed as the number of events per 1,000 invasive mechanical ventilation days of exposure and 95\% confidence interval (CI).

Poisson regression was fitted to the data from D2 to D8 with the observed number of incident VAP as the dependent variable. Time was included as an independent 
variable with the number of invasive mechanical ventilation days at risk as offset in the model. The addition of a quadratic term for time was tested with the likelihood ratio test and conserved to take into account the nonlinearity of incidence with time. Predictions of earlyonset VAP incidence rates at D0 and D1 were based on the final model fitted. This model also estimated missed early-onset VAP occurring within 48 hours after admission. All tests were 2 -tailed, $\mathrm{p}<0.05$ was considered significant. The data were analysed with Stata 8.0 software (Stats Corp. 2003. Stata Statistical Software: Release 8. College Station, TX: StataCorp LP).

\section{Results}

\section{Population characteristics}

A total of 20,640 patients were included in the surveillance in 11 ICUs over the study period. As a whole, 9,322 $(45.2 \%)$ were newly hospitalized patients without immediate previous hospital stay, 9,657 (47.8\%) patients did not receive antibiotics before admission, and 17,302 $(83.8 \%)$ were exposed to mechanical ventilation on the first day of ICU stay.

Overall, data on 3,387 patients (37.6\% women), accounting for 45,760 patient-days, were analyzed. A total of $367(10.8 \%)$ patients developed VAP within the first 9 days of ICU stay. The main patient characteristics are described in Table 1. Median age was 54.3 years (IQR 40-69 years), and median Simplified Acute Physiology Score II was 44 (32-56). Totally, 914 (27.0\%) were trauma patients. Hospital mortality was $21.7 \%$.

\section{VAP incidence}

The mean observed VAP incidence was 20.6 (95\% CI 18.6-22.8) per 1,000 invasive mechanical ventilation days. Table 2 reports the VAP microbiological findings. Figure 1 depicts the distribution of observed and estimated VAP. The predicted cumulative incidence of early-onset VAP at D0 and D1 was 5.3 (95\% CI 2.6-9.8) and 8.3 (95\% CI 6.1-11.1) per 1,000 invasive mechanical ventilation days, respectively (Table 3 ). VAP incidence, estimated by the Poisson model, was 23.0 (95\% CI 20.825.3) per 1,000 invasive mechanical ventilation days at D8. The total proportion of missed early-onset VAP during the first 48 hours of ICU stay was $11 \%$ (95\% CI 9\%-17\%).

\section{Discussion}

The objective of the study was to estimate the incidence of early-onset VAP shortly after admission in ICU. The estimated incidence of early-onset VAP in ICUs within 48 hours after admission was 8.3 (95\% CI 6.1-11.1) per 1,000 invasive mechanical ventilation days. It should be noted that these results cannot be generalized to ICU patient populations because patients were restricted to those at high risk of VAP with mechanical ventilation exposure and no antibiotic use at admission, which might overestimate the daily incidence. Therefore, this sample accounts for a population with high risk of VAP. Indeed, patients who receive antibiotics before ICU admission are at lower risk of VAP $[18,19]$ or VAP within 48 hours after admission [13]. The same is true for

Table 1 Characteristics of patients with or without ventilator-associated pneumonia (VAP) within 9 days of ICU admission in University of Lyon hospitals (France), January 2001-December 2009

\begin{tabular}{|c|c|c|c|}
\hline Characteristics & $\begin{array}{l}\text { VAP within } 9 \text { days } \\
(\mathrm{n}=367)\end{array}$ & No VAP within 9 days $(n=3,020)$ & p-value \\
\hline \multicolumn{4}{|l|}{ Categorical variable, $\mathrm{n}(\%)$} \\
\hline Year of admission & & & $<0.001$ \\
\hline $2001-2003$ & $95(25.9)$ & $1,202(39.8)$ & \\
\hline 2004-2006 & $116(31.6)$ & $937(31.0)$ & \\
\hline 2007-2009 & $156(42.5)$ & $881(29.2)$ & \\
\hline Gender, female & $109(29.7)$ & $1,165(38.6)$ & 0.001 \\
\hline Neutrophil count $<500 / \mathrm{mm}^{3}$ & $23(6.3)$ & $189(6.3)$ & 1.0 \\
\hline Trauma & $160(43.6)$ & $754(25.0)$ & $<0.001$ \\
\hline Diagnosis category & & & $<0.001$ \\
\hline Medical & $152(41.5)$ & $1,844(61.1)$ & \\
\hline Surgical & $214(58.5)$ & $1,176(38.9)$ & \\
\hline Deceased in-hospital & $75(20.5)$ & $656(21.8)$ & 0.6 \\
\hline \multicolumn{4}{|c|}{ Continuous variable, median (interquartile range) } \\
\hline Age, years & $51(36-66)$ & $55(40-69)$ & 0.002 \\
\hline Simplified Acute Physiology Score & $47(36-56)$ & $44(32-56)$ & 0.011 \\
\hline Length of hospital stay, days & $21(12-33)$ & $5(3-12)$ & $<0.001$ \\
\hline Length of intubation, days & $15(9-25)$ & $2(1-8)$ & $<0.001$ \\
\hline
\end{tabular}


Table 2 Microbiological findings on patients who developed ventilator-associated pneumonia in ICUs of University of Lyon hospitals (France), January 2001-December 2009

\begin{tabular}{llllllll}
\hline Microorganism, $\mathbf{n}(\%)$ & Day $\mathbf{2}(\mathbf{n}=\mathbf{5 0})$ & Day $\mathbf{3}(\mathbf{n}=\mathbf{8 2})$ & Day $\mathbf{4}(\mathbf{n}=\mathbf{7 7})$ & Day $\mathbf{5}(\mathbf{n}=\mathbf{5 4})$ & Day $\mathbf{6}(\mathbf{n}=\mathbf{3 1})$ & Day $\mathbf{7}(\mathbf{n}=\mathbf{2 3})$ & Day $\mathbf{8}(\mathbf{n}=\mathbf{2 3})$ \\
\hline Staphylococcus aureus & $18(36)$ & $35(43)$ & $28(36)$ & $23(43)$ & $19(38)$ & $8(26)$ & $6(26)$ \\
Streptococcus pneumoniae & $8(16)$ & $9(11)$ & $11(14)$ & $5(9)$ & $4(8)$ & $3(10)$ & $2(9)$ \\
Haemophilus influenzae & $10(20)$ & $14(17)$ & $16(21)$ & $14(26)$ & $9(18)$ & $4(13)$ & $3(13)$ \\
Pseudomonas aeruginosa & $3(6)$ & $1(1)$ & $5(6)$ & $5(9)$ & $2(4)$ & $3(10)$ & $5(22)$ \\
Enterobacter & $4(8)$ & $5(6)$ & $8(10)$ & $4(7)$ & $4(8)$ & $8(26)$ & $13(39)$ \\
Others & $18(26)$ & $24(29)$ & $17(19)$ & $16(32)$ & $10(32)$ & $4(17)$ & $2(9)$ \\
\hline
\end{tabular}

previously-intubated patients whose VAP risk decreases over time [20].

To the best of our knowledge, data on the incidence of early-onset VAP are sparse. In a prospective study of 250 intubated ICU patients, 32 (12.8\%) incurred VAP within 48 hours [13]; among them, 18 had VAP within 24 hours. However, that study did not provide incidence density, but focused on risk factors for pneumonia within 48 hours of tracheal intubation. The microorganism that they isolated most frequently was Staphylococcus aureus [13]; the same pattern was found for VAP in our study within 9 days. However, Pseudomonas aerugi$n o s a$, infrequent in our series, is a frequent etiological microorganism in VAP [21].

In early-onset VAP, we cannot totally exclude the occurrence of community-acquired pneumonia in the incubation period before admission or early aspiration-associated pneumonia at admission. VAP within 48 hours after hospitalization might be related to the acute period of mechanical ventilation, the severity of the underlying disease or both. Later infections could be associated with chronic exposure to mechanical ventilation and the evolution of the underlying disease. The distinction between acute and chronic risks of VAP might lead to specific preventive measures [19]. In early-onset VAP, the bacteria involved and the risk-factors for pneumonia might be mostly related to the reason for admission. On the other hand, late-onset VAP might be due more to the duration of exposure to invasive mechanical ventilation, quality of care or environmental ecology of the unit.

Our study has some limitations. First, no data were available concerning nasogastric tubes and aspiration, although patients with trauma could suffer aspiration pneumonia. Also, we were unable to control for this risk factor of pneumonia. However, the pathogens found most frequently were not Gram-negative bacilli, which did not suggest aspiration pneumonia. Second, the Glasgow coma scale, which can help to distinguish between VAP and aspiration pneumonia, was not available. Third, the external validity of the results was limited by initial population

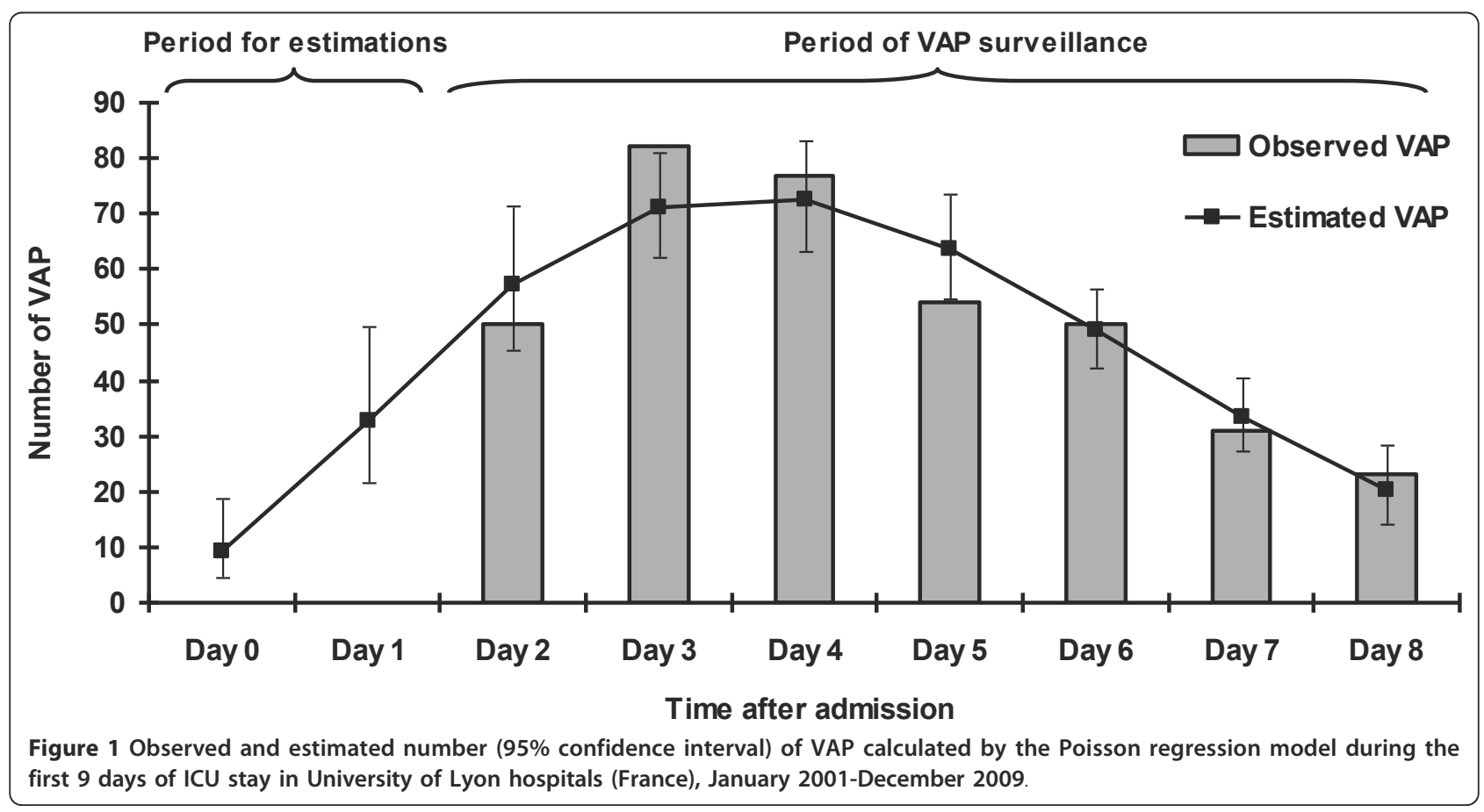


Table 3 Observed and estimated ventilator-associated pneumonia (VAP) in ICUs of University of Lyon hospitals (France), January 2001-December 2009

\begin{tabular}{|c|c|c|c|c|c|c|c|c|c|}
\hline \multirow[b]{2}{*}{ Characteristics } & \multicolumn{4}{|c|}{ Period of VAP estimation } & \multicolumn{3}{|c|}{ Period of VAP surveillance } & \multirow[b]{2}{*}{ Day 7} & \multirow[b]{2}{*}{ Day 8} \\
\hline & Day 0 & Day 1 & Day 2 & Day 3 & Day 4 & Day 5 & Day 6 & & \\
\hline $\begin{array}{l}\text { Observed cumulative invasive } \\
\text { mechanical ventilation days at risk }\end{array}$ & $1,693.5$ & $5,059.5$ & $8,382.5$ & $10,944.5$ & $12,960.5$ & $14,549.5$ & $15,858.5$ & $16,926.5$ & $17,792.5$ \\
\hline Observed number of VAP & - & - & 50 & 82 & 77 & 54 & 50 & 31 & 23 \\
\hline $\begin{array}{l}\text { Estimated number of VAP } \\
(95 \% \mathrm{Cl})\end{array}$ & $\begin{array}{l}9 \\
(5-19)\end{array}$ & $\begin{array}{l}33 \\
(22-50)\end{array}$ & $\begin{array}{l}57 \\
(46-72)\end{array}$ & $\begin{array}{l}71 \\
(62-81)\end{array}$ & $\begin{array}{l}73 \\
(63-83)\end{array}$ & $\begin{array}{l}64 \\
(55-74)\end{array}$ & $\begin{array}{l}49 \\
(42-57)\end{array}$ & $\begin{array}{l}33 \\
(27-40)\end{array}$ & $\begin{array}{l}20 \\
(14-28)\end{array}$ \\
\hline $\begin{array}{l}\text { Observed cumulative incidence of } \\
\operatorname{VAP}(95 \% \mathrm{Cl})\end{array}$ & - & - & $\begin{array}{l}6.0 \\
(4.5-7.8)\end{array}$ & $\begin{array}{l}12.1 \\
(10.1-14.3)\end{array}$ & $\begin{array}{l}16.1 \\
(14.1-18.4)\end{array}$ & $\begin{array}{l}18.1 \\
(16.0-20.4)\end{array}$ & $\begin{array}{l}19.7 \\
(17.6-22.0)\end{array}$ & $\begin{array}{l}20.3 \\
(18.3-22.6)\end{array}$ & $\begin{array}{l}20.6 \\
(18.6-22.8)\end{array}$ \\
\hline $\begin{array}{l}\text { Estimated cumulative incidence of } \\
\operatorname{VAP}(95 \% \mathrm{Cl})\end{array}$ & $\begin{array}{l}5.3 \\
(2.6-9.8)\end{array}$ & $\begin{array}{l}8.3 \\
(6.1-11.1)\end{array}$ & $\begin{array}{l}11.8 \\
(9.7-14.3)\end{array}$ & $\begin{array}{l}15.5 \\
(13.3-18.0)\end{array}$ & $\begin{array}{l}18.8 \\
(16.5-21.2)\end{array}$ & $\begin{array}{l}21.1 \\
(18.8-23.6)\end{array}$ & $\begin{array}{l}22.5 \\
(20.2-24.9)\end{array}$ & $\begin{array}{l}23.0 \\
(20.1-25.4)\end{array}$ & $\begin{array}{l}23.0 \\
(20.8-25.3)\end{array}$ \\
\hline
\end{tabular}

$\mathrm{Cl}$ : confidence interval.

selection. However, this selection permitted us to emphasize the magnitude of the problem in patients with high risk of VAP.

The results need to be confirmed in prospective studies with data on early-onset VAP. Ideally, a large prospective investigation should be undertaken, including patients since the first day of admission, the precise time of exposure to mechanical ventilation as well as nasogastric tubes. Such a study, with microbiological and clinical data collection since the first day of admission, would permit differentiation between communityand hospital-acquired infections. Our results should encourage the surveillance of infection features shortly after ICU admission. In this setting, increased clinical monitoring and vigilance of early-onset VAP as well as early epidemiological surveillance of HAIs should be reinforced. Moreover, the identification of risk factors of early VAP might be helpful to improve clinical care and to prevent these infections.

\section{Conclusions}

In summary, our study suggests possible underestimation of VAP incidence in ICUs. This finding should encourage clinicians to develop a strategy for the quick detection of early-onset VAP shortly after ICU admission. In such a setting, active, early surveillance of VAP features might improve clinical diagnosis and patient outcome. The evaluation of preventive measures against early-onset VAP, immediately after device exposure, should be encouraged.

\footnotetext{
Acknowledgements

We thank Jean-Jacques Lehot, Marc-Olivier Robert, Gérard Fournier, Didier Jacques, François Artru, Pierre-Yves Gueugniaud, Dominique Chassard (intensive care units); Raphaëlle Girard, Jean-Charles Cêtre, Marie-Christine Nicolle, Marie-Hélène Metzger, and Jacqueline Grando (infection control units) as members of the Study Group. We thank Hassane Abidi, Louis Ayzac, Emmanuelle Caillat-Vaillet, Anne Savey (C. CLIN Sud-Est); Monique Bourjault, Marie Celard, Christine Chémorin, Michèle Frêne, Léonne Morandat, Chantal Réat; and Emmanuel Boselli, Bernard Flocard, Christian Guillaume and Pascal Rosamel for their collaboration. Manuscript editing by Ovid Da Silva is acknowledged. Our study received no external funding.
}

\section{Author details}

${ }^{1}$ Hospices Civils de Lyon, Infection Control Unit, Edouard Herriot Hospital, Lyon, France. ' ${ }^{2}$ aboratory of Epidemiology and Public Health, CNRS UMR 5558, University of Lyon, University of Lyon 1, Lyon, France. ${ }^{3}$ Health Care Evaluation Unit, Institute of Social and Preventive Medicine-IUMSP, University of Lausanne, Lausanne, Switzerland. ${ }^{4}$ Hospices Civils de Lyon, Intensive Care Unit, Lyon-South Hospital, Pierre-Bénite, France. ${ }^{5}$ Hospices Civils de Lyon, Surgical Intensive Care Unit, Edouard Herriot Hospital, Lyon, France. ${ }^{6}$ Hospices Civils de Lyon, Medical Intensive Care Unit, Edouard Herriot Hospital, Lyon, France. ${ }^{7}$ Hospices Civils de Lyon, Intensive Care Unit, MotherInfant Hospital, Bron, France. ${ }^{8}$ Hospices Civils de Lyon, Medical Intensive Care Unit, Croix-Rousse Hospital, Lyon, France.

\section{Authors' contributions}

$P V, T B, N V$, and JMJ contributed to the study design and data analysis. PV drafted the initial manuscript. AL, BA, LA, DC, and CG contributed to the analysis and interpretation of data. All authors read, commented on and approved the final manuscript version. The Study Group contributed to the hospital-acquired infection surveillance network.

\section{Competing interests}

The authors declare that they have no competing interests.

Received: 23 March 2011 Accepted: 6 September 2011 Published: 6 September 2011

\section{References}

1. Horan TC, Gaynes RP: Surveillance of nosocomial infections. In Hospital Epidemiology and Infection Control.. 3 edition. Edited by: Mayhall CG. Philadelphia, PA: Lippincott William 2004:1659-1702.

2. Vincent JL, Rello J, Marshall J, Silva E, Anzueto A, Martin CD, Moreno R, Lipman J, Gomersall C, Sakr Y, Reinhart K, EPIC II Group of Investigators: International study of the prevalence and outcomes of infection in intensive care units. JAMA 2009, 302:2323-2329.

3. Verdier R, Parer S, Jean-Pierre H, Dujols P, Picot MC: Impact of an infection control program in an intensive care unit in France. Infect Control Hosp Epidemiol 2006, 27:60-66.

4. Lizan-Garcia M, Peyro R, Cortina M, Crespo MD, Tobias A: Nosocomial infection surveillance in a surgical intensive care unit in Spain, 19962000: a time-trend analysis. Infect Control Hosp Epidemiol 2006, 27:54-59.

5. Garner JS, Jarvis WR, Emori TG, Horan TC, Hughes JM: CDC definitions of nosocomial infections. In APIC Infections Control and Applied Epidemiology: Principles and Practice. Edited by: Olmsted RN. St. Louis, MO: Mosby; 1996: A1-A20.

6. Suetens C, Savey A, Labeeuw J, Morales I, HELICS-ICU: The ICU-HELICS programme: towards European surveillance of hospital-acquired infections in intensive care units. Euro Surveill 2002, 7:127-128.

7. Cohen J, Brun-Buisson C, Torres A, Jorgensen J: Diagnosis of infection in sepsis: an evidence-based review. Crit Care Med 2004, 32(Suppl 11):466-494

8. Depuydt P, Myny D, Blot S: Nosocomial pneumonia: aetiology, diagnosis and treatment. Curr Opin Pulm Med 2006, 12:192-197. 
9. Bagshaw SM, Laupland KB: Epidemiology of intensive care unit-acquired urinary tract infections. Curr Opin Infect Dis 2006, 19:67-71.

10. Lambert ML, Suetens C, Savey A, Palomar M, Hiesmayr M, Morales I, Agodi A, Frank U, Mertens K, Schumacher M, Wolkewitz M: Clinical outcomes of health-care-associated infections and antimicrobial resistance in patients admitted to European intensive-care units: a cohort study. Lancet Infect Dis 2011, 11:30-38.

11. Ostrowsky B: Epidemiology of healthcare associated infections. In Bennett \& Brachman's Hospital Infections.. 5 edition. Edited by: Jarvis WR. Philadelphia, PA: Lippincott Williams 2007:3-24.

12. Chin JC: Control of Communicable Diseases Manual. 17 edition. Washington, DC: American Public Health Association; 2000.

13. Rello J, Diaz E, Roque M, Vallés J: Risk factors for developing pneumonia within 48 hours of intubation. Am J Respir Crit Care Med 1999, 159:1742-1746.

14. Sirvent JM, Torres A, Vidaur L, Armengol J, de Batlle J, Bonet A: Tracheal colonisation within $24 \mathrm{~h}$ of intubation in patients with head trauma: risk factor for developing early-onset ventilator-associated pneumonia. Intensive Care Med 2000, 26:1369-1372.

15. Vanhems P, Lepape A, Savey A, Jambou P, Fabry J: Nosocomial pulmonary infection by antimicrobial-resistant bacteria of patients hospitalized in intensive care units: risk factors and survival. J Hosp Infect 2000, 45:98-106.

16. Pingleton SK, Fagon JY, Leeper KV Jr: Patient selection for clinical investigation of ventilator-associated pneumonia. Criteria for evaluating diagnostic techniques. Chest 1992, 102:553S-556S

17. Fujitani S, Yu VL: Quantitative cultures for diagnosing ventilatorassociated pneumonia: a critique. Clin Infect Dis 2006, 43(Suppl 2) S106-S113.

18. Liberati A, D'Amico R, Pifferi S, Torri V, Brazzi L, Parmelli E: Antibiotic prophylaxis to reduce respiratory tract infections and mortality in adults receiving intensive care. Cochrane Database Syst Rev 2009, CD000022.

19. Sirvent JM, Torres A, El-Ebiary M, Castro P, de Batlle J, Bonet A: Protective effect of intravenously administered cefuroxime against nosocomial pneumonia in patients with structural coma. Am J Respir Crit Care Med 1997, 155:1729-1734.

20. Cook DJ, Walter SD, Cook RJ, Griffith LE, Guyatt GH, Leasa D, Jaeschke RZ, Brun-Buisson C: Incidence of and risk factors for ventilator-associated pneumonia in critically ill patients. Ann Intern Med 1998, 129:433-440.

21. Chastre J, Fagon JY: Ventilator-associated pneumonia. Am J Respir Crit Care Med 2002, 165:867-903.

Pre-publication history

The pre-publication history for this paper can be accessed here: http://www.biomedcentral.com/1471-2334/11/236/prepub

doi:10.1186/1471-2334-11-236

Cite this article as: Vanhems et al.: Early-onset ventilator-associated pneumonia incidence in intensive care units: a surveillance-based study. BMC Infectious Diseases 2011 11:236.

\section{Submit your next manuscript to BioMed Central and take full advantage of:}

- Convenient online submission

- Thorough peer review

- No space constraints or color figure charges

- Immediate publication on acceptance

- Inclusion in PubMed, CAS, Scopus and Google Scholar

- Research which is freely available for redistribution

Submit your manuscript at www.biomedcentral.com/submit 